\title{
The Mediating Role Of EMS Teamwork As It Pertains To HR Factors And Perceived Environmental Performance
}

Bonnie F. Daily, (Email: bdaily@nmsu.edu), New Mexico State University

James W. Bishop, (Email: jbishop@nmsu.edu), New Mexico State University

Robert Steiner, (Email: rsteiner@nmsu.edu), New Mexico State University

\begin{abstract}
Little management theory or empirical results exist to guide managers in maximizing employee efforts to successfully implement Environmental Management Systems (EMS). In response, this study examines the relationship among Human Resource (HR) factors and employee perceptions of environmental performance. Four hundred thirty-seven (437) employees were surveyed in an organization with a well-developed EMS program and ISO 14001 certification. Results suggest that management support for EMS, EMS training, employee empowerment, and EMS rewards are related to perceived environmental performance. Furthermore, EMS teamwork plays a mediating role between some of independent variables and perceived environmental performance. Finally, implications for managers are discussed.
\end{abstract}

\section{INTRODUCTION}

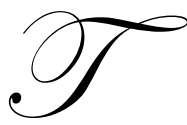

raditionally, many U.S. corporations have used the compliance approach in their environmental programs; as a result, their environmental strategies were driven by laws and regulations. However, in the past several years, environmental forces such as consumer boycotts, dynamic preferences, new customer requirements, and global environmental conventions have affected basic business strategies as well as corporate core values (Berry \& Rondinelli, 1998; Bhushan \& MacKenzie, 1994; Klassen \& Angell, 1998; Klassen \& Whybark, 1999). Consequently, organizations are evolving from a pollution control strategy to a prevention strategy (Brockhoff, Chakrabarti \& Kirchgeorg, 1999; Chen, Hergeth, \& Zuckerman, 2002; Kitazawa \& Sarkis, 2000; Klassen, 2001; Hart, 1997; Porter \& van der Linde, 1995).

To achieve this evolution, many companies seek to develop and deploy a formal Environmental Management System (EMS). An EMS provides a structure that allows management to better control the company's environmental impacts (Barnes, 1996). An integral function of an EMS is to assist firms in improving environmental operations through a system that plans, schedules, implements, and checks daily activities (Hersey, 1998).

Several researchers have argued that certain human resource (HR) factors are particularly salient for successful environmental management (Angell \& Klassen; 1999, Chinander, 2001; Daily \& Huang 2001; Zutshi \& Sohal; 2003). However, only a few empirical studies have examined them in this context (e.g., Carter \& Dresner, 2001; Drumwright, 1994; Rothenberg, Frits, \& Maxwell, 2001; Wee \& Quazi, 2005). While these studies provide initial perspectives on the importance of HR in environmental efforts, none proposed or tested a comprehensive model of essential HR factors or an explanation of the interrelationship between these factors. Our study seeks to fill this void.

The HR factors we identified include management support for the EMS, EMS training, EMS rewards, empowerment, and EMS teamwork. We also examined the relationship these factors have with environmental performance as perceived by the organization's employees. We propose that employee perception of environmental performance is important based on the following reasoning. Motivational theory and associated empirical results 
indicate that workers are more likely to expend considerable effort on tasks when the (1) tasks they do make an important difference and (2) they receive feedback of the results of their effort (Hackman \& Oldham, 1980). In other words the employees' beliefs about the success of their environmental efforts are important relative to their subsequent efforts to achieve environmental goals. Therefore, one purpose of this study is to propose and test a model which links HR factors of a formal, certified EMS (specifically a 14001 certified EMS) to perceived environmental performance (see Figure 1).

FIGURE 1

Hypothesized Model Showing the Hypotheses

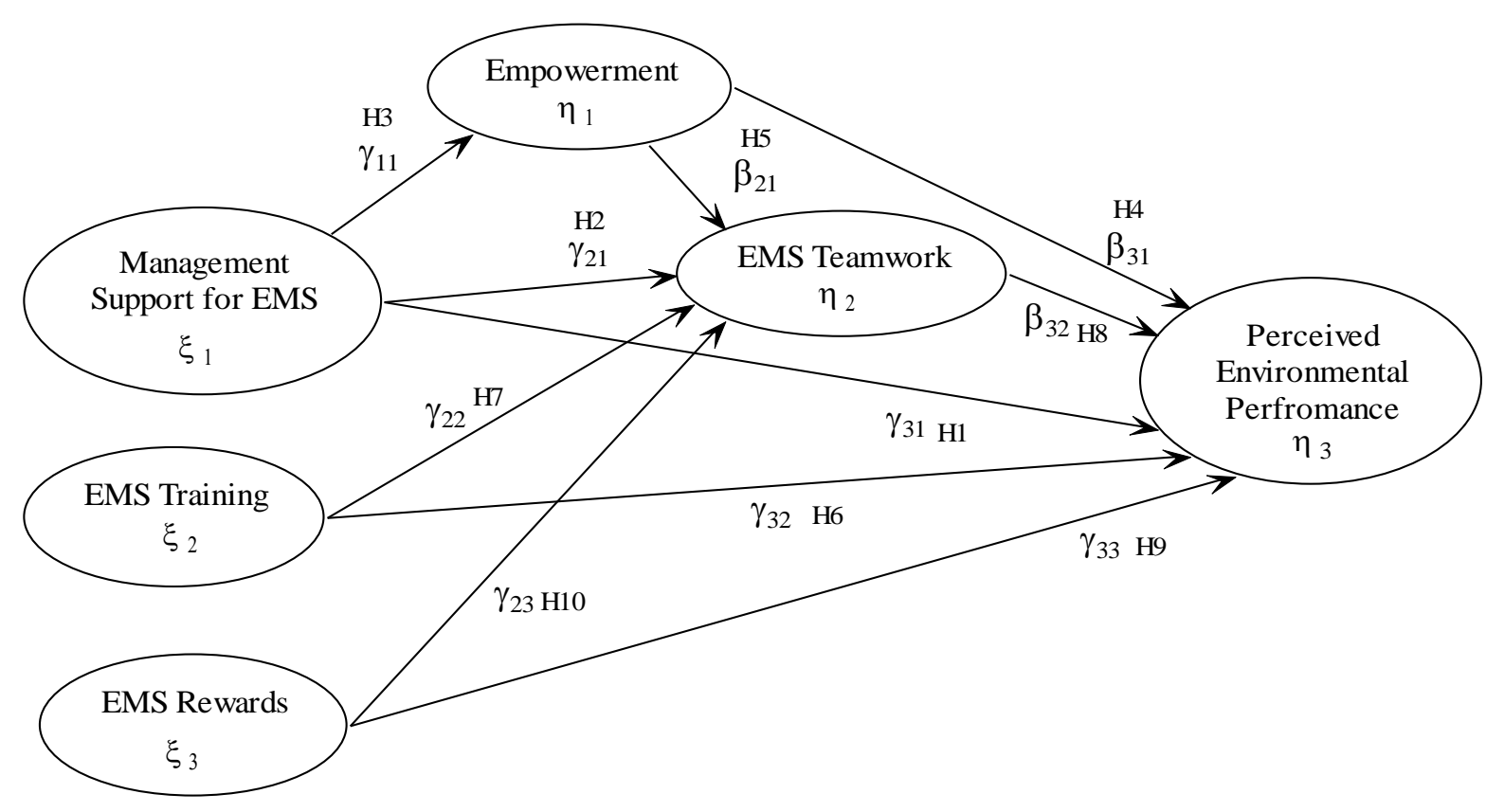

Furthermore, we believe that one particular HR factor, EMS teamwork plays a pivotal role in EMS efforts. On one hand, there is anecdotal evidence suggesting that EMS teamwork is a critical and essential component of environmental initiatives (Beard \& Rees, 2000). On the other hand, little extant research has examined this idea empirically. Hence, the second purpose of this study is to examine EMS teamwork as a mediating variable.

This study extends research on the literatures related to environmental management, human resource management, and teamwork in three ways. First, it proposes a comprehensive model relating HR factors to environmental performance as perceived by the organization's employees. Second, it examines the unique role of teamwork as it relates to environmental issues. Finally, the proposed model provides a linkage across the three literatures through constructs important to each.

\section{HUMAN RESOURCE (HR) FACTORS IN AN EMS}

The discussion of HR factors in environmental management is prevalent (Beard \& Rees, 2000; Bhushan \& Mackenzie, 1994; Carter \& Dresner, 2001; Cook \& Seth, 1992; Daily \& Huang, 2001; Epstein \& Roy, 1997; Govindarajulu \& Daily, 2004; Gupta \& Sharma, 1996; Kitazawa \& Sarkis, 2000; Lent \& Wells, 1994; Mallak \& 
Kurstedt, 1996; Wever \& Vorhauer, 1993; Woods, 1993). However, as previously mentioned, empirical research is scarce. Even so, a few studies have identified relevant HR factors and their use in environmental management. Carter and Dresner (2001) found barriers to environmental project development could be overcome through team structures as well as formal and informal training. Additionally, Drumwright (1994) determined that top management support is conducive to the success of socially responsible buying. Wee and Quazi (2005) identified seven critical factors for environmental management. Included were three were human resource factors: top management commitment, employee involvement, and training. However, they neither proposed nor tested relevant relationships among them or their relationships with performance. Finally, Rothenberg, Frits, and Maxwell (2001) reported a positive relationship between training issues associated with lean manufacturing and resource efficiency.

Because of the scarcity of empirical research addressing HR factors in the environmental literature, we drew upon research from other managerial literature streams for our conceptual base. For example, considerable research indicates that the development of an EMS may parallel that of other well know programs such as Total Quality Management (TQM) (Alm, 1992; Corbett \& Cutler, 2000; Curkovic, 1998; Handfield, et al., 1997; Klassen \& Whybark, 1999; Willig, 1994). Indeed, evidence has been reported suggesting that successful TQM implementation depends upon such HR factors as top management support, training, reward schemes, teamwork, and employee empowerment (Beyerlein, Yeatts, \& Beyerlein, 1991; Chinen, 2000; Daily \& Bishop, 2003; Flynn, Schroeder, \& Sakakibara, 1994; Jayaram, Droge, \& Vickery, 1999; Mohrman, Lawler, \& Ledford, 1996; Saraph, Benson, \& Schroeder, 1989). This research coupled with the environmental literature led us to choose the following HR factors: management support for EMS, EMS training, EMS rewards, EMS teamwork, and employee empowerment for examination.

\section{AN HR FACTORS MODEL OF PERCEIVED ENVIRONMENTAL PERFORMANCE}

\section{Management Support For The EMS}

Management support has been empirically studied and discussed in the quality management, general HR, and organizational behavior literatures as a key component to successful organizational performance and successful implementation of management initiated programs (Ahire et al., 1996; Black \& Porter, 1996; Castellano et al., 1991; Crosby 1979; Deming, 1982; Flynn et al., 1994; Juran 1988; Juran \& Gryna, 1980; Kasul and Motwani, 1995a, 1995b; Motwani, 2001; Powell, 1995, Ross 1991; Saraph et al., 1989; Stickler, 1989; Zeitz et al., 1997). Furthermore, it is one of the most important aspects in the implementation and maintenance of a successful EMS (Daily \& Huang, 2001; Drumwright, 1994; Govindarajulu \& Daily, 2004; Jackson, 1997; Wee and Quazi, 2005; Woodside, Aurrichio, \& Tyurri, 1998). Management support may impact the chance of EMS success by supporting change, promoting employee empowerment to effect change, instituting systems to promote desired behaviors such as rewards or incentive programs, providing training, and communicating information about the EMS throughout the organization (Gupta \& Sharma, 1996; Leitch, Nieves, Burke, Little, \& Gorin, 1995). As Wilms, Hardcastle, and Zell stated, "People will follow management's direction. Whatever management does, and in what direction they push, and how hard they push dictates where this company eventually goes" (1994: 108). In fact, Chinander (2001) proposed that management communication of environmental issues, may affect employee perceptions regarding the linkage of their actions to environmental consequences. Consequently, management can serve as champion of change to help the organization implement the EMS. Hence, we propose that

Hypothesis 1: Management support for the EMS will be positively related to perceived environmental performance ( $\gamma_{31}$ will be positive).

Management support also plays a critical role in introducing and promoting teamwork in an organization (Cohen \& Bailey, 1997; Orsburn, et al., 1990) and readily influences and controls the design of teams to ensure effective organizational outcomes (Magjuka and Baldwin, 1991). That is, management can ensure that teams have access to the information they require, consist of members with diverse job functions and administrative backgrounds, and have a sufficient number of members and other resources required to engage in and accomplish environmental improvement activities. Thus, we propose that 
Hypothesis 2: Management support for the EMS will be positively related to EMS teamwork ( $\gamma_{21}$ will be positive).

The introduction of a new program, such as an EMS, will yield optimal results when employees are treated as major stakeholders in the organization (Mohrman, Lawler, \& Ledford, 1996). Research has suggested that management support provides an atmosphere that can be conducive to empowerment (Ashkenas et al., 1994; Klein, et al., 1995; Kotter, 1995; Balle 1995; Stainer \& Stainer, 2000; Waldman, 1993;Yeh-Yun Lin, 1998). Workers can contribute more effectively when management moves the decision making power down to the employees, allowing them the freedom and power to make suggestions and implement good environmental practices (Wever \& Vorhauer, 1993). Thus we propose that

Hypothesis 3: Management support for the EMS will be positively related to employee empowerment ( $\gamma_{11}$ will be positive).

\section{Employee Empowerment}

Several authors have related this individual empowerment to increased productivity and performance (Gunasekaran \& Cecille, 1998; Leitch et al., 1995; Spreitzer et al., 1997). In particular empowerment has been linked to the facilitation of self-control, individual thinking, and problem solving skills (Cranny, et al., 1992; Gabor, 1990; Korukonda, et al., 1999). Indeed, some of the environmental literature suggests that empowered individuals will have a greater impact on environmental improvements (Daily \& Huang, 2001; Enander \& Pannullo, 1990; Wee \& Quazi; 2005). Moreover, according to Smith, Anderson, and Brooking (1993), in regards to quality efforts, management should delegate to employees authority, time, and resources to define and eliminate waste. Similarly, employee empowerment should be related to environmental improvement. Hence we propose that

Hypothesis 4: Empowerment will be positively related to perceived environmental performance ( $\beta_{31}$ will be positive).

It has been well documented in the management literature that empowerment is an important characteristic for team members to have in order for teams to be successful (Kirkman \& Rosen, 1999; Kirkman, et al., 2001; Korukonda, et al., 1999). In short, successful EMS teamwork requires that team members accept responsibility for and make efforts to accomplish not only individual objectives but team level objectives as well. Since accomplishing team level objectives sometimes means going beyond one's own assigned task, one must operate with a feeling of empowerment. That is, the knowledge that one has the authority to act outside one's individual assignments. We can think of no reason that these concepts would be different for teams assigned to work on environmental issues versus other issues. Therefore, we propose that

Hypothesis 5: Empowerment will be positively related to EMS teamwork ( $\beta_{21}$ will be positive).

\section{EMS Training}

EMS training provides an opportunity to engage employees in environmental problem solving. It makes employees more aware of the need for environmental control, increases their ability to adapt to change, and develops a proactive attitude toward environmental issues (Carter \& Dresner, 2001; Rothenberg, Frits, \& Maxwell, 2001; Wee \& Quazi, 2005; Wong, 1998). Companies also conduct environmental EMS training programs for other reasons such as to inform employees about changes in corporate environmental philosophy, address concerns over increasing environmental liability, and make employees aware of the complexities of the regulatory climate (Cook \& Seith, 1992). Therefore,

Hypothesis 6: EMS training will be positively related to perceived environmental performance $\left(\gamma_{32}\right.$ will be positive).

The management literature abounds with discussions of how training supports teamwork (Coopman, 2001; Lennox, 2001; Marks, et al., 2000). In discussing training for ISO 9000 certification (the quality management 
standards) Cheng and Tummala state:

The training cannot be over-emphasized - not only because the kind of training required is different from what has been traditionally offered, but also it provides team members with the ability to contribute to team objectives. Without training, teams would be similar to committees composed of several members with diverse interests that typically talk a lot and compromise more on a problem than a solution (1998: 862).

Therefore, based upon the preceding we propose a similar relationship with EMS training to EMS teamwork.

Hypothesis 7: $\quad$ EMS training will be positively related to EMS teamwork ( $\gamma_{22}$ will be positive).

\section{EMS Teamwork}

While individual contributions to an organization's environmental efforts are important, EMS teamwork is necessary for a successful environmental management system. Most environmental problems are not individual projects; for example, achieving ten less hazardous spills can be an organizationally-wide project. Essentially the complexities of such problems mandate EMS teamwork (Carter \& Dresner, 2001). Eliminating environmental problems at their sources requires changes and improvements from all organizational areas, including manufacturing, planning, and purchasing (Kitazawa \& Sarkis, 2000; Lent \& Wells, 1994). EMS teamwork provides an opportunity for individuals to come together to find solutions to complex problems. Indeed, the benefits of teams include using collective knowledge to develop comprehensive solutions, avoiding duplication of efforts, and accomplishing many tasks simultaneously (Cai, et al., 1999; Leitch, et al., 1995). According to Daily and Huang (2001), "teamwork is a necessity of a successful environmental management system," (p.1547). Because of the important benefits of teams and teamwork in the use of an EMS, we propose that

Hypothesis 8: EMS teamwork will be positively related to perceived environmental performance ( $\beta_{32}$ will be positive).

\section{EMS Rewards}

EMS rewards can be a reinforcement to continuously motivate and increase commitment from workers to be environmentally responsible (Lent \& Wells, 1994). Furthermore, companies that value environmental performance need to integrate their reward system into their performance evaluation and parallel their performance evaluation system with their environmental objectives (Epstein \& Roy, 1997). In doing this, specific incentives should be implemented for environmental improvement objectives stated in the EMS. Research has shown that reward systems can motivate and reinforce employees to be environmentally responsible (Laabs, 1992; Patton \& Daley, 1998). Based on the preceding discussion, we believe that if reward systems are used systematically to motivate employees to perform desired behaviors with respect to the EMS, then both the company and its workers can benefit and environmental performance will be enhanced. Furthermore, because of the rewards that are offered employees will be aware of the organization's environmental performance. Hence,

Hypothesis 9: EMS rewards will be positively related to perceived environmental performance $\left(\gamma_{33}\right.$ will be positive).

We have suggested EMS teamwork is an important vehicle for employees in an EMS. Hence, EMS rewards for achieving environmental performance should lead individuals to appreciate EMS teamwork more and engage in it more strongly. Thus, we propose that

Hypothesis 10: EMS rewards will be positively related to EMS teamwork ( $\gamma_{23}$ will be positive). 


\section{The Pivotal Role Of EMS Teamwork}

Our model proposes a central role for EMS teamwork. Indeed, based on the logic of the preceding hypotheses, we believe that the strength of the relationships between EMS teamwork and its independent variables (Hypothesis 2, Hypothesis 5, Hypothesis 7, and Hypothesis 10) and its dependent variable, perceived environmental performance (Hypothesis 8), will be such that EMS teamwork will be a significant mediating variable. That is, in each case

Hypothesis 11a, Hypothesis 11b, Hypothesis 11c, Hypothesis 11d: EMS teamwork will mediate the relationships between the following variables and environmental performance: Management support for EMS, employee empowerment, EMS training, and EMS rewards $\left(\gamma_{21} \beta_{32}, \beta_{21} \beta_{32}, \gamma_{22} \beta_{32}\right.$, and $\gamma_{23} \beta_{32}$ will be significant).

\section{METHODS}

\section{Research Site, Sample, And Procedure}

The sample consisted of 437 employees who worked in a large organization in the aerospace field in the Southwestern United States. The facility was ISO 14001 certified. ISO 14001 certification required the development of teams at various levels within and across departments. Also, as part of ISO 14001 certification, the teams were required to participate in environmental training. This EMS training corresponded to management's heavy emphasis on continuous environmental improvement.

\section{Data Collection Procedures}

A questionnaire was administered through a facility web site and participants were assured that their responses would be confidential. All participants were asked to access the web site and fill out the survey. Participants were issued Control ID numbers associated with their departments when they first accessed the web site. This ID was necessary to keep a record of participation and submission. Although, IDs were not related to specific individuals, they were associated with specific departments. Thus, we were made aware that certain IDs had failed to submit information. We then encouraged all department members to finish up the questionnaires without singling out any individuals. The organization had a total of approximately 650 employees at the time of survey. We received 437 responses for a response rate of $67 \%$.

\section{Participants}

Seventy-one percent of the respondents were men, $18 \%$ were women and $11 \%$ failed to identify on gender. Approximately, $1 \%$ of the respondents were African American, 53\% were Anglo/White, $1 \%$ were Asian, 26\% Hispanic, $1 \%$ Native American, $2 \%$ Other and $16 \%$ failed to categorize their ethnicity. Age of participants ranged from 18 to 65 with a mean of 42. Educational background for the participants ranged from high school to Ph.D. level.

\section{Measures}

Because of the parallels between TQM systems and EMS, we measured the constructs of interest using established scales from the TQM literature. We modified these scales by replacing the term "quality" with the term "EMS." The "management support for the EMS" items were from Ahire, Golhar, and Waller (1996) and Hunt (1992); "EMS reward" items were from Hunt (1992), Marchington, Goodman, Wilkinson, and Ackers (1992) and Chinen (2000); "EMS training" items were from Ahire et al (1996); empowerment items were from Sprietzer (1995); "EMS teamwork" items were from Marchington, et al (1992); and "perceived environmental performance" items were from Montabon, Melnky, Sroufe, and Calantone (2000). In all cases, 5-point Likert scales were used with 1 = "strongly disagree" and $5=$ "strongly agree." All items appear in Appendix A.

\section{RESULTS}

The means, standard deviations, coefficient alphas, and correlations among the variables are reported in 
Table 1. Prior to testing our hypotheses, a measurement model using the 23 items that made up our scales was estimated using confirmatory factor analysis $(\mathrm{CFA})$. The model fit the data reasonably well: $\chi_{(215)}^{2}=684.70$; root mean square error of approximation (RMSEA) $=.071$; comparative fit index $(\mathrm{CFI})=.98$; non-normed fit index $(\mathrm{NNFI})=.98$ (Gerbing \& Anderson, 1992; Medsker, Williams, \& Holahan, 1994; Rigdon, 1996). All items loaded significantly on their intended factors. Figure 2 shows the proposed structural model with the measurement components.

TABLE 1

Means, Standard Deviations, Correlations, And Measures Of Reliability Among The Study Variables $(\mathrm{N}=437)$

\begin{tabular}{|c|c|c|c|c|c|c|c|c|c|}
\hline & Variable & Mean & SD & 1 & 2 & 3 & 4 & 5 & 6 \\
\hline$\overline{1}$ & Management support for EMS & 3.83 & .86 & $(.91)$ & & & & & \\
\hline 2. & EMS rewards & 3.18 & .88 & $0.51^{* * * *}$ & $(.80)$ & & & & \\
\hline 3. & EMS training & 3.32 & .91 & $0.64^{* * *}$ & $0.63^{* * *}$ & $(.91)$ & & & \\
\hline 4. & Empowerment & 4.28 & .78 & $0.43^{* * *}$ & $0.19^{* * * *}$ & $0.23^{* * * *}$ & $(.83)$ & & \\
\hline 5. & EMS teamwork & 3.26 & .86 & $0.58^{* * *}$ & $0.66^{* * *}$ & $0.78^{* * * *}$ & $0.18^{* * *}$ & $(.88)$ & \\
\hline 6. & Environmental performance & 3.52 & .85 & $0.64^{* * *}$ & $0.59^{* * * *}$ & $0.62^{* * *}$ & $0.34^{* * *}$ & $0.68^{* * * *}$ & $(.91)$ \\
\hline
\end{tabular}

FIGURE 2

Hypothesized Model Showing the Measurement Portion

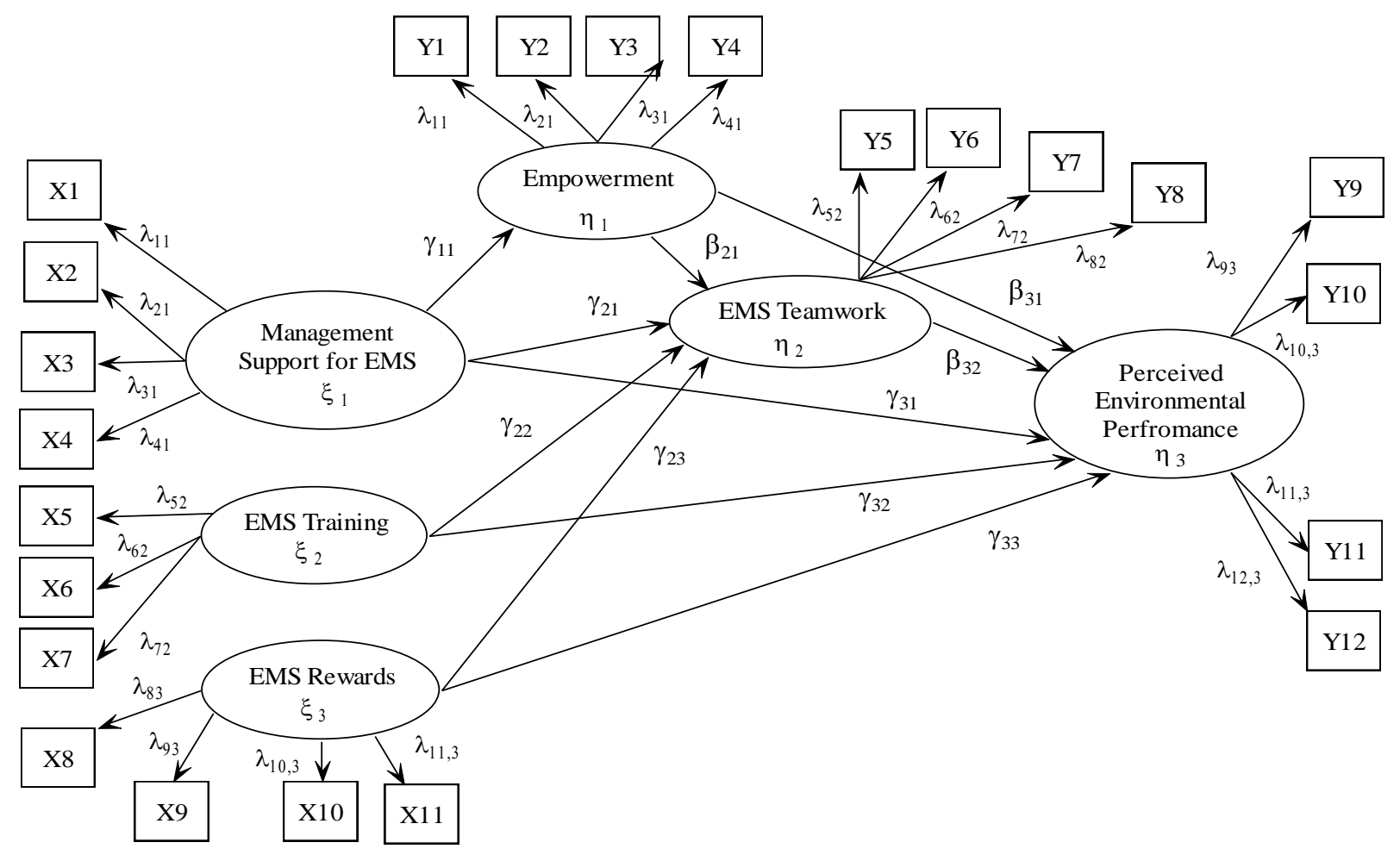

\section{Hypothesized Structural Model}

The hypothesized model (see Figure 3) was tested with an item-level structural equation model. The model accounted for $76 \%$ of the variance in EMS teamwork, $20 \%$ of the variance in empowerment and $66 \%$ of the variance 
in perceived environmental performance. Fit indices indicated the model fit the data well: $\chi^{2}{ }_{(217)}=693.58$, RMSEA $=$ $.070, \mathrm{CFI}=.98$, and NNFI $=.98$. Figure 3 shows completely standardized path coefficients. Completely standardized coefficients are reported because of their suitability in comparing relative contributions to explained variance (Bagozzi, 1980).

FIGURE 3

Structural Path Estimates ${ }^{+}$

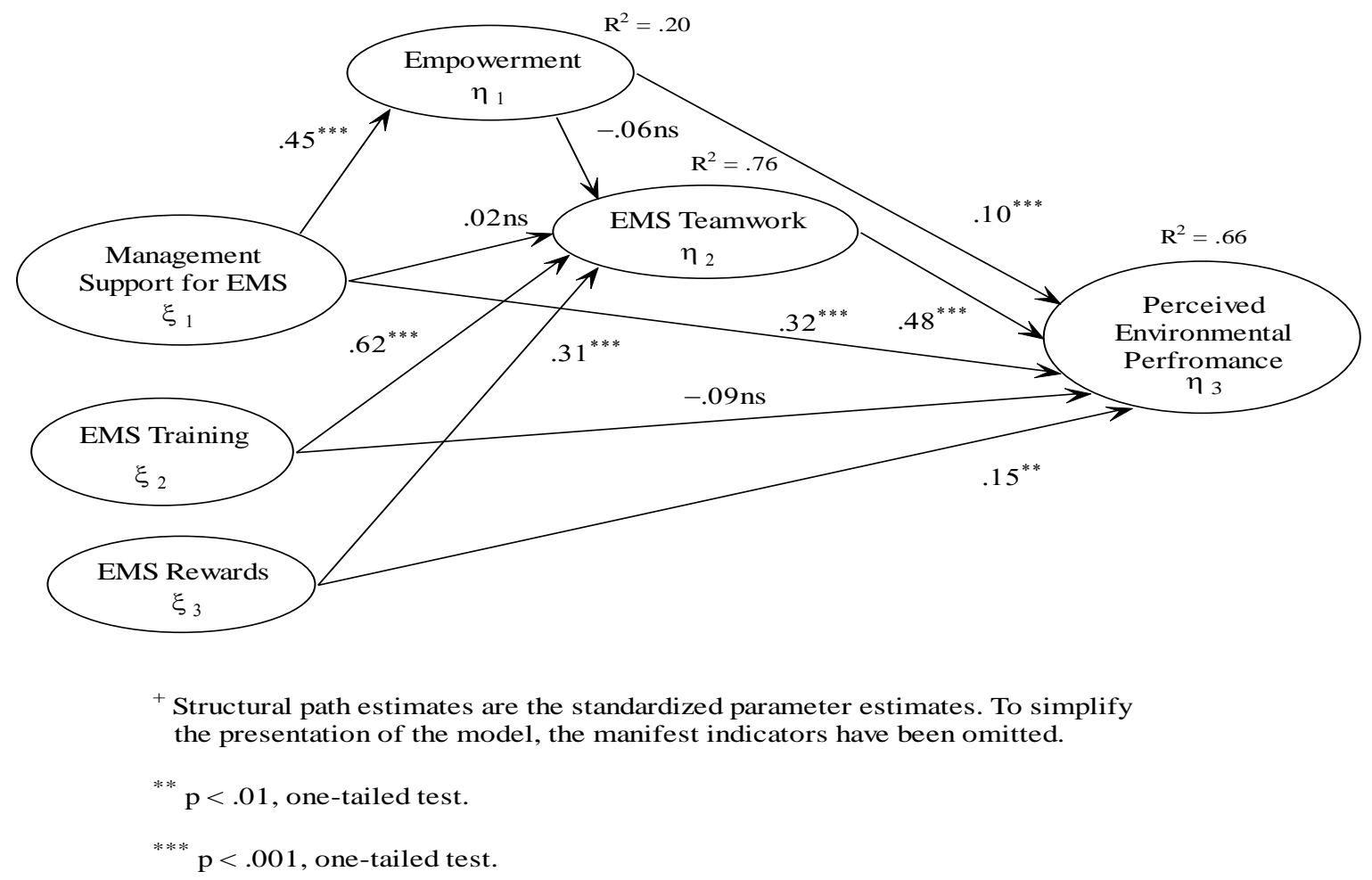

\section{Direct Relationships}

The paths from management support for the EMS to perceived environmental performance and empowerment were significant, supporting Hypotheses 1 and 3, respectively. However, the path from management support for the EMS to EMS teamwork was not significant, hence, Hypothesis 2 was not supported. The path from empowerment to perceived environmental performance was significant, while the one from empowerment to EMS teamwork was not. Hence, Hypothesis 4 was supported while Hypothesis 5 was not. The path from EMS training to perceived environmental performance was not significant while the path from EMS training to EMS teamwork was. Hence Hypothesis 6 was not supported while Hypothesis 7 was. The path from EMS teamwork to perceived environmental performance was significant providing support for Hypothesis 8. The path from EMS rewards to perceived environmental performance and to EMS teamwork were significant, supporting Hypotheses 9 and 10, respectively.

\section{Mediating Role Of EMS Teamwork}

We also tested the indirect effects of management support for EMS, empowerment, EMS training, and EMS rewards on perceived environmental performance through EMS teamwork. Using the technique recommended by Sobel (1987), estimations for the indirect effects, their standard errors, and 95\% confidence intervals (CI) were 
computed given, as input, the maximum likelihood path coefficients and their standard errors. In the case of the indirect effects of management support for EMS and empowerment on perceived environmental performance through EMS teamwork, this test was not required because the paths from management support for the EMS and empowerment to EMS teamwork were not significant. Hence, Hypotheses 11a and 11b were not supported.

The indirect path $\left(\gamma_{22} \beta_{32}\right)$ from EMS training to perceived environmental performance through teamwork was $.15 \pm .076(\underline{\mathrm{SE}}=.039)$ and the $95 \% \mathrm{CI}$ did not contain zero. Thus EMS teamwork completely mediates the effect of EMS training on perceived environmental performance, supporting Hypothesis 11c. Similarly, Hypothesis 11d was supported since $\gamma_{23} \beta_{32}=.132 \pm .062(\underline{\mathrm{SE}}=.032)$ and the $95 \% \mathrm{CI}$ did not contain zero.

\section{Other Statistical Analyses}

We considered the possibility that the department in which the individual worked may have biased his or her evaluation of perceived environmental performance. If this was the case it would suggest a violation of the SEM assumption of independent responses. Therefore, we calculated the intra-class correlation coefficient (ICC(1)) to determine the amount of variance of perceived environmental performance which was due to department membership. We found this to be less than 3\%, suggesting that the respondents were little influenced by their departmental membership. We also calculated the ICC(1) for all other variables and found that the greatest amount of variance that could be attributed to department membership was related to the EMS teamwork variable and that was less than $4 \%$. Consequently, we concluded that the assumption of the independent responses was not violated. All ICC(1) values are reported in Table 2.

TABLE 2

Influence Of Departmental Membership On Survey Responses

\begin{tabular}{lc}
\hline Construct & ICC(1) \\
\hline Environmental performance & 0.0286 \\
Empowerment & 0.0245 \\
Management support for EMS & 0.0333 \\
Reward & 0.0340 \\
EMS training & 0.0180 \\
EMS teamwork & 0.0393 \\
\hline
\end{tabular}

\section{DISCUSSION AND CONCLUSIONS}

This study contributes to environmental studies in several ways. First, it tested a model in which the proposed relationships among HR factors and perceived environmental performance were based on sound theory. The importance of these HR factors with respect to environmental performance has been proposed before, but until now why they were important and how they were related among each other and with the dependent variable remained unexplored.

Second, this study demonstrated the unique and pivotal role played by EMS. This was emphasized by the mediating role EMS teamwork plays between EMS training and EMS rewards with perceived environmental performance.

Our hypothesized model proposed 10 direct relationships including five between HR factors (management support for EMS, EMS training, EMS rewards, and empowerment) and perceived environmental performance and four to EMS teamwork from the other HR factors. Seven of these relationships were significantly different from zero. We also hypothesized 4 indirect relationships through teamwork to perceived environmental performance and 2 were significant. The indirect relationship from EMS training was fully mediated while that from EMS rewards was partially mediated. Overall, our model explained $66 \%$ of the variance in perceived environmental performance. This implies that management controlled processes and activities can have a significant impact on environmental performance, at least as perceived by employees. As proposed, EMS teamwork played an important mediating role 
between HR factors and perceived environmental performance.

Five of our hypotheses failed to receive support. These failures were predicated on three paths being nonsignificant, two to EMS teamwork from empowerment and management support for the EMS and one from EMS training to environmental performance. In the case of empowerment to EMS teamwork, some respondents may have considered empowerment as a condition only related to their individual jobs and unrelated to working in EMS teams.

The case of management support for EMS to EMS teamwork is more puzzling to us. Perhaps employees did not see a connection between management support for the EMS and the fact that management put teams in place for the expressed purpose of enhancing perceived environmental performance. We would not have thought that this would be the case, particularly in light of the result that both EMS teamwork and management support for the EMS are significantly related to perceived environmental performance. We conclude that further conceptual work followed by empirical research is required in order to determine in greater detail the role of management support in implementing an EMS and subsequent perceived environmental performance.

The case of the path from EMS training to environmental performance being non-significant is also puzzling to us. It may have been that EMS teamwork completely mediates the relationship between EMS training and perceived environmental performance because much of environmental problem solving is boundary spanning. That is, EMS training's relationship with EMS performance is manifested through EMS teamwork.

In any case, our results suggest that managers should carefully consider human resource factors when implementing an EMS/ISO 14001. Managerial support for an EMS should be strong and highly visible. Top management within an environmentally conscious organization should strive for and support a work environment that allows its employees the freedom to make environmental improvements. Our results also support the contention by Mallak and Kurstedt (1996) that an environmentally conscious organization should empower its employees. In particular they should be empowered to make environmental improvements without excessive management intervention, allowed to make inputs for improvement, and given time for experimentation (Woods, 1993). EMS teamwork should be emphasized due to its significant mediating role as reported in our model. EMS training in support of environmental team endeavors should be provided competently and in a timely manner and an appropriate reward system should be implemented.

As with all field research, this study has some limitations that must be acknowledged. Common method variance is a concern with studies of this type. In his review of the role of self-reports in behavioral research, Spector concluded "the reasonableness of using self-reports depends upon the purpose of the study" (1994, p. 387) and "properly developed instruments are resistant to the method variance problem" (1994, p. 438).

Another possible limitation of our study is the use of perceived environmental performance rather than a more objective measure. While we made the case for the importance and usefulness of employee perceptions of environmental performance, future research should focus on the accuracy of employee perceptions as compared with more objective measures.

As with all studies involving a sample from a single organization, generalizability of the findings should be a concern. While every organization has its own culture and set of norms, we believe that the ISO 14001 standards provide a degree of uniformity and commonality in developing an environmental management system. We believe that those organizations who have ISO 14001 certification have an environmental management system that is more similar than those who do not have ISO 14001certification. For this reason, we believe that concerns about the generalizability of our findings should be attenuated to a considerable degree. Even so, we certainly acknowledge that the generalizability of this study as well as all studies of this type can be enhanced by replication studies involving multiple organizations.

Establishment of an EMS or certification for ISO 14001 can enhance a business' ability to control and prevent environmental problems. A reduction of environmental problems generally increases efficiencies and productivity for a business while improving the opportunities for sustainability within a society. However, 
implementation of these systems requires considerable investments of time, energy and finances. Therefore, implementation of an EMS should be conducted in a thoughtful, structured manner. Our model provides an understanding of how HR factors may relate to EMS initiatives.

\section{APPENDIX A: Questionnaire Items}

Empowerment items:

1. My job activities are personally meaningful to me.

2. I I am confident about my ability to do my job.

3. I have mastered the skills necessary for my job.

4. I can decide on my own how to go about doing my job.

Management support for EMS items:

5. Top management at our facility treats EMS as an important issue.

6. Top management at our facility allocates adequate resources to EMS efforts.

7. Top management at out facility allows employees to spend time on EMS efforts.

8. Top management at our facility follows up suggestions for improvement on EMS.

EMS Rewards items:

9. We are rewarded for making suggestions for improvement on EMS.

10. Supervisors in my department give credit to people when they work on EMS improvements.

11. Our facility provides individual financial incentives for EMS improvements.

EMS training items:

12. We have many opportunities to get EMS training about EMS in our facility.

13. We get EMS training frequently.

14. Everybody in this facility can get a chance to be trained on EMS issues.

15. I am satisfied with the EMS training provided by our facility.

EMS teamwork items:

16. We frequently use EMS teamwork to solve EMS problems.

17. We get a great amount of EMS information from our EMS teamwork.

18. I have an opportunity to express my opinion about EMS issues in team meetings.

19. People in our facility attend team meetings on EMS frequently.

EMS environmental performance items:

20. Our facility's EMS efforts have significantly reduced waste within the production process.

21. Our facility's EMS efforts have significantly improved product quality.

22. Focusing on EMS has enhanced our facility's reputation.

23. Our facility's EMS efforts have lead to improved facility performance. 


\section{REFERENCES}

1. Angell, L. C., Klassen, R. D. 1999. Integrating environmental issues into the mainstream: an agenda for research in operations management. Journal of Operations Management, 17: 575-598.

2. Ahire, S. L., Golhar, D.Y., Waller, M .A., 1996. Development and validation of TQM implementation constructs. Decision Science, 27(1): 23-56.

3. Alm, A.L., 1992. Pollution prevention and TQM. Environmental Science Technology, 26(3): 452.

4. Ashkenas, R. N., Hsaffer, R. H., \& Associates, 1994. Beyond the fads: how leaders drive change with results. Human Resource Planning, 17(2): 25-44.

5. $\quad$ Bagozzi, R. P., 1980. Causal modeling in marketing, John Wiley \& Sons, New York.

6. Bansal, P. Hunter T. 2003. Strategic explanations for the early adoption of ISO 14001. Journal of Business Ethics, 46(3): 289-299.

7. $\quad$ Barnes, P.E., 1996. Green standards. $B \&$ E Review (Oct/Dec): 24-28.

8. Beard, C. and Rees S., 2000. Green teams and the management of environmental change in a UK county council. Environmental Management and Health, 11: 27-38.

9. $\quad$ Begley, R., 1996. Is ISO 14000 worth it? Journal of Business Strategy, 17; 50-55.

10. Berry, M.A. and Rondinelli, D. A., 1998. Proactive corporate environmental management: A new industrial revolution. Academy of Management Executive, 12: 38-50.

11. Beyerlein, S.T., Yeatts, D. E., and Beyerlein M. M., 1991. Antecedents and consequences of role stress in a Greenfield site: A covariance structure analysis. Paper presented at the International Conference on Selfmanaged work teams, Dallas.

12. Bhushan, A.K. and MacKenzie, J. C., 1994. Environmental leadership plus total quality management equals continuous improvement, in J.T. Willig (Ed.), Environmental TQM (2 ${ }^{\text {nd }}$ Ed.): 72-93. McGraw-Hill, New York.

13. Black S. and Porter L. 1996. Identification of the critical factors of TQM, Decision Sciences, 27: 1-21.

14. Block, M. R., 2004. ISO 14001 revision nears completion, Quality Progress, 37(2): 77-80.

15. Brockhoff, K., Chakrabarti, A. K., Kirchgeorg, M., 1999. Corporate strategies in environmental management. Research Technology Management, 44(4): 26-30.

16. Cai, S., Daily, B., and Jun, M., 1999. Employee involvement: A conceptual model of process and effects. Proceedings of the National Decision Sciences Institute Conference, New Orleans: 1362-1364.

17. Carter, C. R. and Dressner, M., 2001, Purchasing's Role in Environmental Management: Cross-Functional Development of Grounded Theory, The Journal of Supply Chain Management: 12-27.

18. Castellano, J. Klein, D., and Roehm, H. 1991. Springing to world class manufacturing, Management Accounting, March: 40-4.

19. Chen, A. .S., Hergeth, H., and Zuckerman, G. J. 2002. Environmentally Conscious Manufacturing Through Total Cost Management. Journal of Applied Business Research, 18(3): 15-22.

20. Chinander K., 2001. Aligning accountability and awareness for perceived environmental performance in operations. Production and Operations Management, 10: 276-291.

21. Chinen, K., 2000. The relationships between total quality management factors and work outcomes in a Maquiladora. Unpublished doctoral dissertation, New Mexico State University, Las Cruces, New Mexico.

22. Cohen, S. G. and Bailey, D. E., 1997. What makes teams work: Group effectiveness research from the shop floor to the executive suite, Journal of Management, 23: 239-290.

23. Cook, J. and Seith, B. J., 1992. Designing an effective environmental EMS training program. Journal of Environmental Regulation, 2(1): 53-62.

24. Coopman, S. J., 2001. Democracy, performance, and outcomes in interdisciplinary health care teams. The Journal Of Business Communication 38(3): 261-284.

25. Corbett, C. J. and Kirsh, D. A., 2001. International diffusion of ISO 14000 certification. Production and Operations Management, 10(3): 327-342.

26. Corbett, L. M. and Cutler, D. J., 2000. Environmental management systems in the New Zealand plastic industry. International Journal of Operations and Production Management, 20(2): 204-224.

27. Cranny, C. J., Smith P. C., and Stone, E. F., 1992. Job Satisfaction: How People Feel About Their Jobs And How It Affects Performance, Lexington Books, New York.

28. Crosby, P. 1979. Quality is Free, McGraw-Hill, New York. 
29. Curkovic, S., 1998. Investigating the linkage between total quality management and environmentally responsible manufacturing, UMI Dissertation Services, UMI 9839628.

30. Daily, B. and Bishop, J., 2003. TQM workforce factors and employee involvement: the pivotal role of teamwork, Journal of Managerial Issues, 14(4): 393-412.

31. Daily, B. F. and Huang, S., 2001. Achieving sustainability through attention to human resource factors in environmental management, International Journal of Operations \& Production Management, 21: 1539-1552.

32. Deming, W. E. 1982. Out of the Crisis. MIT Center for Advanced Educational Services, Cambridge.

33. Drumwright, M. E. 1994. Socially Responsible Organizational Buying: Environmental Concern as a Noneconomic Buying Criterion. Journal of Marketing, 58: 1-19.

34. Enander, R.T. and Pannullo, D., 1990. Employee involvement and pollution prevention. The Journal for Quality and Participation, July/August: 50-53.

35. Epstein, M. J. and Roy, M., 1997. Using ISO 14000 for improved organizational learning and environmental management. Environmental Quality Management, 7: 21-30.

36. Flynn, B., Schroeder, R. G., and Sakakibara, S., 1994. A framework for quality management research and an associated measurement instrument. Journal of Operation Management, 11: 339-366.

37. Gabor, A., 1990. The Man Who Discovered Quality: How W. Edwards Deming Brought The Quality Revolution To America: The Stories Of Ford, Xerox, And GM, Times Books, New York.

38. Gerbing, D. W. and Anderson, J. C., 1992. Monte Carlo evaluations of goodness of fit indices for structural equation models. Sociological Methods and Research, 21: 132-160.

39. Govindarajulu, N. and Daily, B. F. 2004. Motivating Employees for Environmental Improvement. Industrial Management and Data Systems, 104: 364-372.

40. Gunasekaran, A. and Cecille, P., 1998. Experience of a small company in productivity improvement. Production and Inventory Management Journal, 39(2): 49-54.

41. Gupta, M. and Sharma, K., 1996. Environmental operations management: An opportunity for improvement. Production and Inventory Management Journal, 37(3): 40-46.

42. Hackman, J.R. and Oldham, G.R. (1980). Work redesign. Reading, MA, Addison-Wesley

43. Handfield, R. B., Walton, S. V., Seegers, L. K., and Melnyk, S. A., 1997, Green value chain practices in the furniture industry. Journal of Operations Management, 15: 293-315.

44. Hart, S. L., 1997. Beyond greening: Strategies for a sustainable world. Harvard Business Review, 75(1): 6676.

45. Hersey, K., 1998. A close look at ISO 14000, Professional Safety, 43(7): 26-29.

46. Hunt, V.D., 1992. Quality in America: How to implement a competitive quality program, Business One, Irwin, Illinois.

47. Jackson, S. L., 1997. The ISO 14001 implementation guide, John Wiley \& Sons, Inc., New York.

48. Jayaram, J., Droge, C., and Vickery, S. K., 1999. The impact of human resource management practices on manufacturing performance. Journal of Operations Management, 18: 1-20.

49. Johnson, P.L., 1997. The ISO 14000 road map to registration, McGraw-Hill, New York.

50. Juran, J.M. 1988. Juran On Planning For Quality, Free Press, New York.

51. Juran, J. M. and Gryna, 1980. Quality Planning And Analysis, McGraw-Hill, New York

52. Kasul, R. and Motwani, J. 1995a. Performance measurements in world-class operations, Benchmarking for Quality Management \& Technology, 2(2): 20-36.

53. Kasul, R. and Motwani, J. 1995b. Total quality management in manufacturing: Thematic factor Assessment, International Journal of Quality and Reliability Management, 2(3): 57-76.

54. Kitazawa, S. and Sarkis, J., 2000. The relationship between ISO 14000 and continuous source reduction. International Journal of Operations \& Production Management, 20(2): 225-248.

55. Klassen, R. D., 2001. Plant-level environmental management orientation: The influence of management views and plant characteristics. Production and Operations Management, 10(3): 257-275.

56. Klassen, R. D.A. and Whybark, D. C., 1999. The impact of environmental technologies on manufacturing performance. Academy of Management Journal, 42: 599-615.

57. Klassen, R. D. and Angell, L. C., 1998. An international comparison of environmental management in operations: The impact of manufacturing flexibility in the U.S. and Germany. The Journal of Operations Management, 16(2/3): 177-194. 
58. Klein, A., Masi, R., and Weidner, C., 1995. Organizational culture, distribution, and amount of control, and perceptions of quality, Group and Organization Management, 20: 122-48.

59. Kirkman, B. L. and Rosen, B., 1999. Beyond self management: Antecedents and consequences of team empowerment, Academy of Management Journal, 42: 58-74.

60. Kirkman, B. L., Tesluk, P. E., and Rosen, B., 2001. Assessing the incremental validity of team consensus rating over aggregation of individual-level data in predicting team effectiveness, Personnel Psychology, 54: 645-667.

61. Korukonda, A. R., Watson, J.G., and Rajkumar T. M., 1999. Beyond Teams and empowerment: A counterpoint to two common precepts in TQM, S.A.M. Advanced Management Journal, 64: 29-36.

62. Kotter, J. P. 1995. Leading change: why transformation efforts fail, Harvard Business Review, 67(6): 85-92.

63. Laabs, J. J., 1992. The greening of HR. Personnel Journal, Aug.: 60-71.

64. Leitch, J., Nieves, D., Burke, G., Little, M., and Gorin, M., 1995. Strategies for involving employees. The Journal for Quality and Participation, 18(5):, 68-74.

65. Lennox, J. M., 2001. Team-building for a better tomorrow. Journal of Property Management, 66(5): 10-11.

66. Lent, T. and Wells, R. P., 1994. Corporate environmental management survey shows shift from compliance to strategy, in J.T. Willig (Ed.), Environmental TQM (2 ${ }^{\text {nd }}$ Ed.): 8-32 McGraw-Hill, New York.

67. Magjuka, R. J. and Baldwin, T. T., 1991. Team-based employee involvement programs: Effects of design and administration. Personnel Psychology, 44: 793-812.

68. Mallak, L.A. and Kurstedt, H. A., 1996. Understanding and using empowerment to change organizational culture. Industrial Management, 38(6): 8-10.

69. Marchington, M., Goodman, J., Wilkinson, A., and Ackers, P., 1992. New developments in employee involvement. Employment Department Research, series No2.

70. Marks, M.A., Mathieu, J. E., and Zaccaro, S. J., 2000. Performance implications for briefings and team interaction EMS training for team adaptation to novel environments. Journal of Applied Psychology, 85: 971986.

71. Medsker, G. J., Williams, L. J., and Holahan, P. J., 1994. A review of current practices for evaluating causal models in organizational behavior and human resource management research. Journal of Management, 20 : 439-464.

72. Mohrman, S.A., Lawler, E. E., and Ledford, G. E., 1996. Do employee involvement and TQM programs work? Journal for Quality and Participation, Jan/Feb: 6-10.

73. Montabon, F., Melnyk, S. A., Sroufe, R., and Calantone, R. J., 2000. ISO 14000: Assessing its perceived impact on corporate performance. Journal of Supply Chain Management, 36(2): 4-16.

74. Motwani, J., 2001, Critical factors and performance measures of TQM, The TQM Magazine, 13(4): 292-300.

75. Orsburns, J. D., Moran, L., Musselwhite, E., and Zenger, J.H., Self-Directed Work Teams: The New American Challenge, Irwin, New York.

76. Patton, K. R. and Daley, D. M., 1998. Gainsharing in Zebulon: What do workers want? Public Personnel Management, Spring: 117-131.

77. Porter, M.E. and Van der Linde, C., 1995. Green and competitive: Ending the stalemate. Harvard Business Review, 73(5): 120-34.

78. Powell, T. C., 1995. Total quality management as competitive advantage: A review and empirical study, Strategic Management Study, 16: 15-37.

79. Rigdon, E. E., 1996. CFI Versus RMSEA: A comparison of two fit indexes for structural equation modeling. Structural Equation Modeling, 3: 369-379.

80. Ross, D. F., 1991. Aligning the organization for world class manufacturing, P \& IM Review, 32(2): $22-26$.

81. Rothenberg, S., 2001. Knowledge content and worker participation in environmental management, Working Paper, Rochester Institute of Technology, Rochester, NY.

82. Saraph, J.V., Benson, P. G., and Schroeder, R. G., 1989. An instrument for measuring the critical factors of quality management. Decision Science, 20: 810-829.

83. Smith, P.A., Anderson, W. D., and Brooking, S. A., 1993. Employee empowerment: A case study. Production and Inventory Management, 34(3): 45-50.

84. Sobel, M. E., 1987. Direct and indirect effects in linear structural equation models. Sociological Methods \& Research, 16: 155-176. 
85. Spector, P. E. 1994. Using self-report questionnaires in OB research: A comment on the use of a controversial method. Journal of Organizational Behavior, 15: 385-392.

86. Spector, P. E., and Brannick, M. T. 1995. The nature and effects of method variance in organizational research. In C. L. Cooper and I. T. Robertson (Eds.) International Review of Industrial and Organizational Psychology, 10: 249-274. John Wiley, Chichester.

87. Spreitzer, G. M., 1995. Psychological empowerment in the workplace: Dimensions, measurement, and validation. Academy of Management Journal(38): 1442-1465.

88. Spreitzer, G. M., Kizilios, M. A., and Nason, S. W. 1997. A dimensional analysis of the relationship between psychological empowerment and effectiveness, satisfaction, and strain, Journal of Management, 23: 679-704.

89. Stainer, A. and Stainer, L., 2000. Empowerment and strategic change-an ethical perspective, Strategic Change, 9(5): 287-296.

90. Stickler, M. J. 1989. Going for the glove, part II - eliminating waste, $P$ \& IM Review, November: $32-34$.

91. Waldman, D. 1993. A theoretical consideration of leadership and total quality management, Leadership Quarterly, 4: 65-79.

92. Wever, G.H. and Vorhauer, G. F., 1993. Kodak's framework and assessment tool for implementing TQEM. Total Quality Environmental Management, 3(1): 19-30.

93. Willig, J., 1994. Environmental TQM, McGraw-Hill, New York.

94. Wilms, W.W., Hardcastle, A. J., and Zell, D. M., 1994, Cultural transformation at NUMMI. Sloan Management Review, 36: 99-113.

95. Wong, W.Y.L., 1998. A holistic perspective on quality quests and quality gains: The role of environment. Total Quality Management, 9, 4/5: S241-S245.

96. Woods, S., 1993. Making pollution prevention part of the Coors culture. Total Quality Environmental Management, 3(1): 31-38.

97. Woodside, G., Aurrichio, P., and Yturri, J., 1998. ISO 14001, McGraw-Hill, New York.

98. Yeh-Yun Lin, C., 1998. The essence of empowerment: A conceptual model and a case illustration, Journal of Applied Management Studies, 7: 223-238.

99. Zeitz, G., Johannesson, R., and Ritchie, J. E. 1997. An employee survey measuring total quality management practices and culture, Group and Organization Management, 22: 414-444.

100. Zutshi, A. and Sohal, A. S. 2003. Stakeholder involvement in the EMS adoption process. Business Process Management Journal, 9(2): 133-148. 


\section{NOTES}

